\title{
Erratum to: Episodic memory impairment in Addison's disease: results from a telephonic cognitive assessment
}

\author{
Michelle Henry • Kevin G. F. Thomas • Ian L. Ross
}

Published online: 30 March 2014

(C) Springer Science+Business Media New York 2014

Erratum to: Metab Brain Dis

DOI 10.1007/s11011-014-9511-x

A co-author's name was omitted from the original version of this article. The list of authors is now corrected in the authorgroup of this article.

The online version of the original article can be found at http://dx.doi.org/ 10.1007/s11011-014-9511-x.

M. Henry $(\bowtie) \cdot$ K. G. F. Thomas

University of Cape Town, Rondebosch, Western Cape, South Africa

e-mail:mhmish@gmail.com

I. L. Ross

Department of Endocrinology, Groote Schuur Hospital, University of

Cape Town, Rondebosch, South Africa 7701 